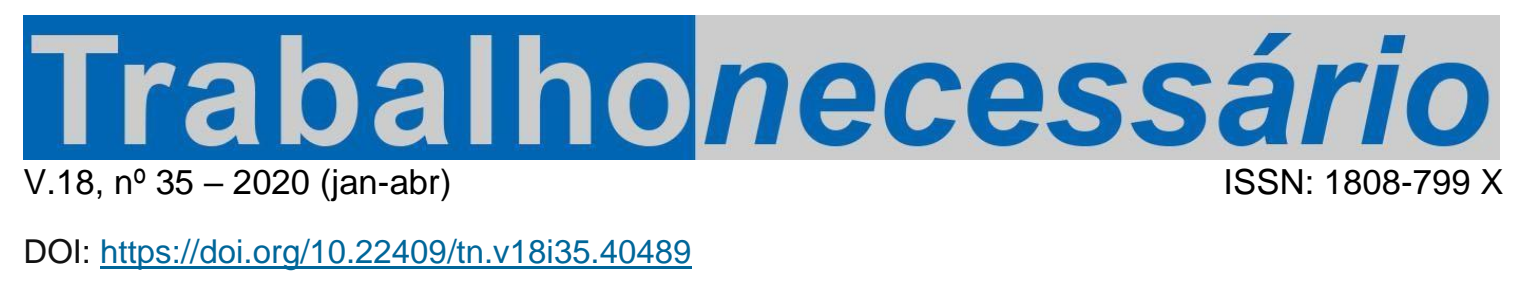

\title{
Apresentação
}

\section{HISTÓRIA E HISTORIOGRAFIA EM TRABALHO-EDUCAÇÃO E O PENSAMENTO CRÍTICO}

\author{
Maria Ciavatta - Grupo These (UFF/UERJ/Fiocruz) ${ }^{1}$
}

O historiador Jean Chesnais pergunta: "Que lugar ocupa o saber histórico na vida social? Atua a favor da ordem estabelecida ou contra ela?" Na historiografia em trabalho-educação, perguntamos, em que consiste o pensamento crítico em um mundo que cresce em conhecimento e em novos poderes científico-tecnológicos. Mas cresce, também, no volume de pessoas desamparadas, de migrantes, de pessoas pobres em todas as dimensões da necessidade de bens, para ter uma vida digna, acossados pela sedução da publicidade do consumo fácil, pelas mentiras edulcoradas de verdade.

O termo pensamento crítico², como outros termos e conceitos, tem sido apropriado por ideologias diferentes do significado que lhe atribuem os grupos onde foram produzidos. No senso comum, a crítica é uma censura, um julgamento desfavorável. Mas tem origem no grego krísis que significa julgamento, critério, decisão, debate, desatar um nó. O pensamento crítico é aquele que não fica na aparência, mas utiliza critérios de discernimento que se referem a vários aspectos de uma questão, que "desatam nós", mostram aspectos não evidentes, não revelados.

\footnotetext{
${ }^{1}$ Licenciada em Filosofia, Doutora em Ciências Humanas (Educação), Professora Titular em Trabalho e Educação da Universidade Federal Fluminense, Niterói, Rio de Janeiro, mciavatta@terra.com.br. ORCID: 0000-0002-2374-2627.

${ }^{2}$ Esta reflexão consta, originalmente, de CIAVATTA, Maria. O Golpe Civil-militar e o pensamento crítico em trabalho e educação Seminário de Produção Científica do Grupo THESE, UFF, UERJ e EPSJVFiocruz, dezembro de 2014.
} 
O pensamento crítico é fundamental para entendermos nosso país. Convivemos com o desmonte das estruturas de democratização da sociedade, que foram conquistas das instituições renovadas, dos partidos políticos e dos movimentos sociais, após vinte anos de ditadura (1964-1985). "A eleição do populismo autoritário de direita como rejeição ao establishment político uniu, no Brasil, a agenda do conservadorismo moralista ao fundamentalismo de mercado". ${ }^{3}$ A verdade não edulcorada que se nos revela é de difícil aceitação. Vemos a perda de direitos conquistados com a contrarreforma e a desregulamentação do trabalho, com a dubiedade na obediência à Constituição Federal, o corte nos programas sociais, o aumento do desemprego e da desigualdade de acesso à moradia, à saúde, educação, segurança.

A ciência, as universidades públicas, os institutos de pesquisa, as instituições de arte e cultura, o teatro, a música e o cinema enfrentam um dia a dia de corte de recursos básicos, combinado a critérios inverossímeis de censura moral e política. "Terra plana, ideias rasas. Há alguma coisa muito errada quando é preciso reabrir a discussão sobre a esfericidade da terra. Voltamos ao pré-iluminismo? Fomos transportados para algum ponto anterior ao século XVII?" 4

A ordem estabelecida no Brasil, a partir das eleições presidenciais de 2018, desafia todos os critérios da modernidade, porque o poder governamental atua segundo o próprio arbítrio, à revelia da tradição das instituições democráticas, impondo a ortodoxia econômica liberal, implantada no Chile pela ditadura de Pinochet (1973-1990). Em vez da comunicação oficial de governo, desde seu início, operam as redes sociais manipuladas pela família presidencial, as fake news, o antiintelectualismo, a guerra contra o chamado "marxismo cultural", a criminalização das políticas institucionais, atingindo a produção cinematográfica e teatral, o desmatamento e as queimadas autorizadas, a omissão diante da invasão de terrar indígenas, a privatização da educação pública e dos serviços básicos de saúde, a militarização das escolas, as investidas contra a autonomia dos professores...

\footnotetext{
${ }^{3}$ CARVALHO, Laura. A fórmula explosiva do bolsonarismo. Folha de São Paulo, llustríssima, dom., 1‥ De dezembro de 2019, p. 6.

${ }^{4}$ ALCÂNTARA, Eurípedes. Terra plana, ideias rasas. O Globo, Opinião, sáb., 2 de novembro de 2019, p. 3
} 
Pensar historicamente, ${ }^{5}$ "consiste em compreender e esforçar-se por fazer compreender os fenômenos sociais na dinâmica de suas sequências"6. Significa buscar compreender a realidade nas múltiplas mediações que a constituem, identificar seus sujeitos sociais, no espaço-tempo em que trabalham, vivem e se educam para a vida social em toda a sua complexidade.

Para Marx e Engels ${ }^{7}$ a história é a produção social da existência, nos atos de comer, abrigar-se, reproduzir-se, criar os meios de vida na interação com a natureza e com os demais seres humanos. Assim se produz e reproduz a vida, cria-se a cultura em todas as formas que conhecemos.

Do ponto de vista teórico-metodológico, significa considerar a história como processo e a história como método de pesquisa. A história como o processo real da vida dos homens em sociedade, os acontecimentos, as estruturas, os sujeitos sociais. A história como método, como sua representação ao nível do pensamento, seus relatos e narrativas. A historiografia é a análise crítica da história escrita, o amadurecimento do campo científico que pensa sobre seu próprio fazer.

Passado e futuro se expressam no presente, no instante de cada momento em que se contempla ou se deplora a vida. Para Antoine Prost, o historiador olha o passado em função das questões do presente: "A história faz-se a partir do tempo, um tempo complexo, construído e multifacetado"8. A dimensão social dos fenômenos deve ser buscada no espaço-tempo social dos tempos complexos dos fenômenos da vida humana, o que nos leva a ver que a historicidade do momento que vivemos supõe uma concepção dialética do espaço-tempo e o tratamento dos fenômenos sociais na sua temporalidade múltipla de que fala Braudel. ${ }^{9}$

Qual o lugar da história em um ambiente onde a ciência secular é desafiada por declarações inconsequentes? Do que deve se ocupar a história da educação e do trabalho-educação no exame científico e crítico dos fatos que são objeto dos estudos históricos? Quais os critérios de cientificidade? Muitas são as vertentes analíticas

\footnotetext{
${ }^{5}$ Parte destas reflexões constam de CIAVATTA, Maria. "Ensaio sobre a lucidez" e a realidade brasileira. Democracia, violência, anti-intelectualismo. XIII Colóquio Nacional e VI Colóquio Internacional do Museu Pedagógico, Universidade do Estado da Bahia, Vitória da Conquista, 15 a 18 de outubro de 2019 ,

${ }^{6}$ VILAR, Pierre. Pensar a história. México, DF: Instituto Mora, 1992.

${ }^{7}$ MARX ENGELS. A ideologia alemã (Feurbach). São Paulo: Ciências Humanas, 1979.

${ }^{8}$ PROST, Antoine. Doze lições sobre história. Belo Horizonte: Autêntica, 2008, p. 96.

${ }^{9}$ BRAUDEL, Fernand. A longa duração. In: Presença, 1982. História e Ciências Sociais. Lisboa: Editorial
} 
pelas quais os historiadores relatam os acontecimentos e escrevem a história dos indivíduos e dos povos. Nós nos situamos no materialismo histórico dialético (MARX, 1980 entre outros) ${ }^{10}$ que permite compreender o modo de produzir a vida nos últimos séculos, e constatar o acirramento das contradições entre a reprodução e a acumulação do capital e o empobrecimento e abandono generalizado das populações. De modo complementar, procuramos fazer a interlocução com outras vertentes historiográficas, algumas das quais presentes neste número temático da Revista Trabalho Necessário.

Com o apoio dos pareceristas e dos editores, estabelecemos dois critérios básicos para organização da TN 35: o primeiro é a pertinência ao campo da história da educação e questões referentes ao mundo do trabalho-educação em suas particularidades, tais como, as relações entre o capital e o trabalho, seus vínculos com a sociedade, a educação profissional, as políticas educacionais e sua expressão na cultura material em espaços formativos, o uso das imagens e de outras fontes documentais sobre a preparação para o trabalho na escola, nas empresas, nos movimentos sociais, na saúde etc.

O segundo critério foi o mérito acadêmico-científico na elaboração do tema e sua articulação com processos de pesquisa. Do ponto de vista teórico, a contradição capital e trabalho e a aceitação da luta de classes como motor da história ${ }^{11}$ não está presente em todos os trabalhos aqui apresentados. O que não significa que não escrevam a história da educação profissional e de outros temas afins. Prevaleceu nossa opção pela interlocução com a história e a historiografia do trabalho-educação.

A seção Artigos do Número Temático é composta por dez artigos, sendo um internacional. Inicia com o trabalho de Vitor Benvindo, que encontra no materialismo histórico um recurso teórico para a compreensão da "atual conjuntura de avanço do pensamento conservador e reacionário em todo mundo", realizando a escrita da história "a contrapelo", nos termos do filósofo Walter Benjamin. "Em tempos de avanço do obscurantismo, "clarear essa obscuridade" "é a honra da pesquisa histórica", diz o autor, com base na concepção de história presente nas obras de Marx e Engels. A história, assim escrita, obriga a ver o mundo real, onde vivemos nas suas contradições geradas pelo conjunto das forças sociais e seus projetos individuais, de grupos e

\footnotetext{
${ }^{10}$ MARX, Karl. O capital (Crírica da Economia Política). Rio de Janeiro; Civilização Brasileira, 1980.

${ }^{11}$ MARX, Karl; ENGELS, Friedrich. Manifesto do Partido Comunista. São Paulo: Cortez, 1998 , p. 4.
} 
classes. Do "desafio de compreender a cultura e a ideologia como elementos fundamentais da luta de classes, emerge um segundo desafio, o de perceber 0 movimento da história não apenas como o "cortejo triunfal dos vencedores, dos dominadores", mas também o outro lado da história, os ganhos históricos dos vencidos.

O trabalho de Dalton José Alves situa-se na historiografia de longa duração, revelando a natureza da escola. "A escola surge, assim, como 'Scholé"” (lugar do ócio), mas não era um lugar de descanso ou de lazer, ao contrário, era "o lugar para onde eram enviados aqueles que não precisavam trabalhar para viver. Os filhos dos proprietários." Será o "modelo geral de educação para todos". Na Modernidade inaugurada pelo pensamento burguês, em particular com a Revolução Industrial, aplica-se à "pedagogia da hegemonia da classe proprietária, antes feudal" e, depois, capitalista. O restante da população destina-se ao aprendizado para os processos produtivos, em uma sociedade que parte do "trabalho centrado na indústria e na cidade, oriundo da organização do trabalho na manufatura capitalista". Ao longo dos séculos, torna-se o "princípio educativo por excelência da escola pública para todos". Compreendemos hoje suas contradições porque "O conhecimento da história do ser e estar humano no mundo passa pela compreensão do papel do trabalho e da educação no processo de humanização".

Maria de Fátima Félix Rosar trata da "história recente das relações entre capital, trabalho e desenvolvimento humano". A autora busca "agudizar a perspectiva crítica da historiografia da educação, dada a necessidade histórica de se realizar o enfrentamento das investidas do capital". A ciência, a educação e a cultura são desprovidas de seu potencial emancipatório quando apropriadas como mercadorias. Tendo em conta a perspectiva histórica de longa duração, argumenta que a "relação entre trabalho e condição digna de vida não se sustenta no âmbito das relações sociais de produção, desde os primórdios da história do Brasil." Essa racionalidade mundial sustenta-se nas crises sucessivas do capitalismo, na ideologia neoliberal, na "incorporação da biotecnologia, genética, robótica, informática, telecomunicações, transporte" modificando a percepção das dimensões espaciais e temporais, e levando ao poder regimes autoritários e ultraconservadores, como no caso atual, o Brasil. A partir de Marx e de Agnes Heller, considera as necessidades humanas materiais, básicas para a sobrevivência e as necessidades decorrentes no âmbito da liberdade 
e da emancipação. Destaca ainda "as experiências no 'mundo do trabalho associado"” e as geradas na educação como "embriões de educação para além do capital".

Carlos Alberto Lucena traz um relato etnográfico, denso de história política, sobre a greve dos petroleiros de 1995, a partir da memória dos petroleiros da base, de dirigentes e de militantes dos sindicatos de trabalhadores. "Se a história de todas as sociedades até hoje é a história das lutas de classes" como afirmam Marx e Engels $^{12}$ nas primeiras linhas do Manifesto Comunista, o autor deste artigo nos apresenta um retrato vivo dos longos processos de decisão dos trabalhadores na construção de uma greve de reivindicação e de enfrentamento com o "Governo Federal, o corpo diretivo da Petrobras e a mídia brasileira para desestabilizar o movimento paredista" no início do primeiro governo neoliberal de F. H. Cardoso. O texto remete aos processos de "financeirização das economias e à mundialização do capital", "às formas de obtenção de mais-valia absoluta e relativa em sua dinâmica de reprodução do capital composto de juros" do Livro Terceiro de O Capital de Marx. Deste ponto de vista, a greve também poderia ser analisada como "resistência a um amplo processo de subordinação da periferia ao centro do capitalismo manifesto em privatizações e quebra de monopólios estatais". É um texto exemplar da história viva das difíceis tentativas de emancipação dos trabalhadores frente ao capital e à totalidade social de seus vínculos com o Estado, a mídia impressa e televisiva e as instituições em processo de democratização.

A contribuição de Michelle Freitas Teixeira situa-se no eixo teórico marxista gramsciano para o estudo da luta por hegemonia na educação de jovens e adultos e na educação rural. O foco principal da pesquisa, em desenvolvimento, tem início nos anos 1990. É o "Movimento Por Uma Educação do Campo, ao qual integram diversos organismos privados campesinos, dentre eles o Movimento do Trabalhadores Rurais Sem Terra (MST). No campo da cultura e da educação, os movimentos sociais resistem à formação restrita, tanto de uma "mão de obra disciplinada para o trabalho assalariado rural quanto de consumidores de produtos agropecuários". O artigo fundamenta sua "análise teórico-metodológica da concepção de Estado" como "Estado Ampliado"; na história como produção social, "processo real da vida humana em sociedade"; nas contradições que permeiam as relações entre o capital e o trabalho; e na "disputa por diferentes projetos de educação para a classe trabalhadora

\footnotetext{
${ }^{12}$ MARX; ENGELS, ibid.
} 
rural". Os estudos e pesquisas sobre a organização da classe trabalhadora supõem "pensar as bases, os fundamentos, as categorias que se alinham a um projeto que se faça coerente à luta contra hegemônica contra o "projeto de capitalismo agrário no período de avanço da contrarreforma capitalista neoliberal no Brasil". A autora observa a presença agressiva do "capitalismo empresarial nas relações produtivas do campo alicerçadas na difusão do projeto do agronegócio e articuladas ao processo de reorganização da sociabilidade do capital."

Tendo, como foco específico, a relação entre o trabalho e a educação, Patrícia Furtado Fernandes Costa e Lucília Regina de Souza Machado têm por base um levantamento das "referências históricas e teóricas para a análise crítica da produção do conhecimento no Brasil sobre currículo integrado e ensino médio integrado." Seu ponto de partida é o debate sobre currículo integrado e ensino médio integrado na história da educação brasileira a partir da Lei n. 9.394/1996 e as iniciativas de regulamentação sobre a educação profissional. Seu debate, amplo e polêmico, "fez emergir o conceito de formação humana integral, suas várias dimensões, seus obstáculos advindos das contradições sociais" repondo, em termos atualizados até os dias de hoje, a dualidade estrutural da sociedade de classes do país. A formação integrada é um tema recorrente na literatura científica educacional desde 2004. Ela faz parte de um projeto em disputa na sociedade brasileira: a educação geral, integral, omnilateral e de qualidade no ensino médio público, ou seu estreitamento na preparação para a ordem, a disciplina e a preparação funcional no trabalho simples para o mercado. Além da documentação legal apresentada, dos anos 1970 a 2017, as autoras recuperam ampla bibliografia analítica sobre a questão, remetendo alguns aspectos aos primórdios da educação no Brasil do século XIX e na antiguidade ocidental.

Os quatro artigos que se seguem contemplam a historiografia da educação profissional com diferentes abordagens: sobre as fontes de um arquivo institucional; a escrita de professores de uma escola polivalente, em um periódico local; a educação profissional e a instituição escola do Império à Primeira República.

Olívia Morais de Medeiros Neta e Francisco das Chagas Silva Souza tratam da "historicidade da educação profissional: o portal da memória do IFRN e a democratização da memória institucional." O Portal do Instituto Federal do Rio Grande do Norte disponibiliza documentação referente à "história das instituições, cultura 
escolar, currículo, cultura material escolar e sociabilidades." Além da história e da memória institucional, o Portal democratiza o acesso às informações que revelam a historicidade do IFRN que, em 2009, comemorou 100 anos de existência, por ter sido uma das 19 Escolas de Aprendizes Artífices criadas em 1919. "O Portal também se preocupa em registrar, por meio de imagens fotográficas e relatos orais gravados em vídeos, algumas práticas do cotidiano da instituição que dizem respeito à cultura escolar". Citado pelos autores, para Marc Bloch 13 "o passado é, por definição, um dado em que nada mais modificará. Mas o conhecimento do passado é uma coisa em progresso, que incessantemente se transforma e se aperfeiçoa". O Portal da Memória, "como arquivo/museu escolar digital, nasceu com o desenvolvimento das novas tecnologias da comunicação geradas pela memória eletrônica, na segunda metade do século XX." Como outras fontes, seu uso e pertinência na historiografia depende das perguntas que Ihes são feitas pelos historiadores, adverte Le Goff14: "O Portal representa um potencial instrumento de democratização da memória na modernidade, ao acabar as fronteiras físicas e temporais entre os sujeitos que o acessam, [mas] é também um desafio, visto que representa um novo modo de produzir, registrar e guardar a memória no mundo contemporâneo."

Maria Augusta Martiarena de Oliveira tem, como fonte principal de pesquisa, a imprensa pedagógica, a Revista Polivisão, que está disponível no Arquivo Histórico da cidade de Osório, RS. São artigos que registram a visão do ensino integrado pelos docentes da Escola Polivalente, a Escola Maria Teresa Vilanova Castilhos, da cidade de Osório, RS, em 1986, logo após o fim da ditadura e a redemocratização do país. A "instituição integrou uma rede de escolas criadas no âmbito dos acordos entre o Ministério da Educação (MEC) e a Agência Internacional para o Desenvolvimento (USAID)." A Escola contava com boa estrutura física, amplas salas de aula, além de salas específicas para as disciplinas técnicas (industriais, comerciais, agrícolas e domésticas), mas nas análises indicam que visava "a relação entre assistencialismo e atendimento ao mercado". Não obstante, teriam atuado "no sentido de manutenção dos estudantes na escola e na vida escolar", em um período de movimentos de greve do magistério estadual, entre o final da década de 1980 e a década de 1990. Em 1982,

\footnotetext{
${ }^{13} \mathrm{BLOCH}$, Marc. Apologia da história ou o ofício do historiador. Rio de Janeiro: Jorge Zahar Editor, 2001, p. 75.

${ }^{14}$ LE GOFF, Jacques. História e memória. 5. ed. Campinas-SP: Editora da Unicamp, 2003, p. 463.
} 
a Lei n. 7.044, tornara opcional a profissionalização compulsória prescrita pela $\mathrm{n}$. 5.692/71 e o Parecer n 895/71, mas, "diferentemente do que era pautado pela legislação, os docentes preocupavam-se com uma formação integral". Além do termo integrado, algumas categorias eram básicas na concepção dos docentes para a análise da educação polivalente naquele $A$ contextualização e o espaço político da redemocratização incorporam a crítica à "hegemonia estrangeira, principalmente dos Estados Unidos, [que] é amplamente criticada, bem como o papel periférico/marginal ocupado pelo Brasil na esfera global".

No sentido de historicizar a Educação Profissional do Império à Primeira República, José António Martin Moreno Afonso e Renato Marinho Brandão Santos, retomam um tema comum na sociologia histórica do século $X X$, que é o conceito de "classes perigosas" para designar a população abandonada pelo poder público, remanescente de um processo de libertação dos escravos que foi uma medida de lei, a Lei Áurea n.․ 3.353, de 13 de maio de 1988, que nunca completou a integração social e política dos libertos. A sociedade das elites, os brancos, nunca promoveu os meios de vida (moradia, trabalho, saúde, educação, segurança), dignos e suficientes para essa população. Diante da desigualdade e da exclusão social, o medo dos ricos e o ressentimento dos pobres, as "classes populares", geraram a defesa e rigor punitivo "à ociosidade, mãe de todos os vícios" nos primeiros; e resistência através do fortalecimento das culturas de origem, agressão e revoltas nos segundos. Os autores estudam o ensino profissional no Brasil, "desde os Liceus e Casas de Educandos, no período imperial, até as Escolas de Aprendizes estabelecidas nas capitais brasileiras a partir de 1910, durante a Primeira República". Assim, foi possível observar, ao longo dos períodos, "a associação entre o ensino profissional e o controle das denominadas "classes perigosas". O controle das "classes populares" e o "culto ao trabalho" para os "desfavorecidos da fortuna" alimentaram a criação de várias instituições de ensino profissional no Império e na Primeira República.

O artigo de Francisco Carlos Oliveira de Sousa dá continuidade à história do ensino profissional na Primeira República, particularmente, a Rede de Aprendizes Artífices, criada em 1909, pelo Presidente Nilo Peçanha. "A análise das fontes apoia- 
se nos referenciais propostos por Magalhães (2004), Nosella e Buffa (2007), ${ }^{15}$ segundo os quais, compreender a genealogia de uma instituição educativa pressupõe relacionar a sua função social e o contexto no qual está inserida." As Escolas de Aprendizes Artífices dão continuidade à política de governos anteriores e posteriores, de destinar aos escravos, aos libertos e a seus filhos o ensino das práticas laborais, em detrimento da educação. Mas o foco do artigo é compreender a escola em sua historicidade e natureza institucional, e aos seus determinantes do modo de produção capitalista ."Como possibilitar a incorporação da população aos novos preceitos políticos, sociais e culturais que a nova era prometia?" Eram crescentes os problemas sociais e a agitação da incipiente classe operária dos primórdios do industrialismo. Apesar da pretendida modernização com a criação dos grupos escolares para a educação elementar no final do século XIX, a instituição escolar na Primeira República caracterizou-se pela "importância dos ofícios manuais, em suas dimensões preventiva e corretiva". ${ }^{16}$

$\mathrm{Na}$ seção Ensaio encontramos importante reflexão enviada pelo professor Juan Mainer Basqué, da Fundação Icaria (Espanha), outra contribuição internacional apresentada na TN 35. Em uma perspectiva histórica crítico-genealógica, no texto Fábricas de Inequidad: crítica de la escuela capitalista, o autor analisa que, longe de promover a igualdade social, os sistemas escolares têm se constituído como elementos eficazes para legitimação e consagração da estrutura de classes, do colonialismo e da segregação de gênero. Para ele, por ser a instituição escolar um espaço de debate e de luta, é fundamental submeter à crítica equivocadas concepções de educação, cultura e ensino que têm embasado o pensamento dos setores da esquerda.

Na seção Documentário, em O Rio dos Trabalhadores - a educação do olhar e a fotografia como fonte histórica, Maria Ciavatta apresenta contribuições teóricometodológicas em relação a como podemos fazer história e historiografia de maneira a compreender e interpretar os mundos do trabalho e do capital. Por meio da

\footnotetext{
${ }^{15}$ MAGALHÃES, Justino. Tecendo nexos: história das instituições educativas. Bragança Paulista: Editora Universitária São Francisco, 2004.

NOSELLA, Paolo; BUFFA, Ester. Instituições escolares: porque e como pesquisar. Campinas: Alínea, 2009.

${ }^{16}$ CUNHA, Luiz Antônio. $O$ ensino de ofícios nos primórdios da industrialização. São Paulo: Editora UNESP, Brasília: Flacso, 2000, p. 24, grifo do autor do artigo.
} 
fotografia, entendida como fonte histórica, pode-se educar o olhar, com a perspectiva de desconstruir os caminhos do capital e sua influência na vida das cidades, na conformação da classe trabalhadora. Além do texto de apresentação, o leitor poderá acessar o link do vídeo.

Na seção Resenha, os autores José Lúcio Nascimento Júnior e Patrícia Maria Pereira do Nascimento tecem considerações sobre a obra "A historiografia em Trabalho-Educação: como se escreve a história da educação profissional, de Maria Ciavatta et al. Contendo a participação de diversos pesquisadores, a obra "marca a posição de um campo de estudo", na medida em que são poucos os estudos que tentam fortalecer e entender as tramas que compõem a história e historiografia em Educação Profissional. Como aborda o prefaciador do livro, o Prof. Gaudêncio Frigotto, a obra recupera o papel da história, ou seja, a história entendida como processo e como método. Navegam os autores por diferentes contextos históricos, mas fincam o pé no Brasil Republicano. A obra é resultado de vários trabalhos de pesquisa e de organização e realização de seminários sobre o tema.

A TN 35 conta também com a seção Artigos de Demanda Contínua, a qual contém 4 interessantes textos.

Com o propósito de refletir sobre limites das políticas públicas educativas na atual fase de desenvolvimento do capitalismo, Antonio Nascimento da Silva, Deribaldo Santos e George Amaral nos brindam com o artigo Educação na Crítica ao Programa de Gotha: uma síntese. Para os autores, referendando a perspectiva marxiana, Lassalle estava equivocado ao pretender, enquanto proposta revolucionária de um partido comunista, obter do Estado as condições e o apoio para estruturar uma educação alinhada aos propósitos comunistas. Isto porque, o Estado, como gerenciador dos interesses da burguesia, apenas concederá formação para os trabalhadores na medida em que tal formação contribua para perpetuar a ordem constituída. Como afirma Marx na "Crítica ao Programa de Gotha" "é o Estado que, ao contrário, necessita receber do povo uma educação muito rigorosa".

Tendo a perspectiva de analisar as políticas para o campo da educação na atualidade, o artigo de Catia Eli Gemelli intitulado A quem serve a 'neutralidade'? Análise do Movimento Escola Sem Partido à luz da ideologia gerencialista, aborda os projetos de lei que foram apresentados nos poderes legislativos do Brasil, tendo estes o objetivo de "combater a doutrinação ideológica" no ensino. Para além da profusão 
da ideologia gerencialista, tais projetos são pensados como proposta para os espaços educacionais numa retomada do discurso de defesa de uma educação tecnicista, com uma nova roupagem: traz-se a teoria de capital humano, pensada nos anos 50-70 do século XX, para uma nova aplicação no Século XXI. Junta-se a essa teoria a onda neoconservadora e seus fundamentalismos diversos (econômico, religioso e político), trazidos pelos projetos. Com o artigo, além dos conceitos e categorias próprios do método que adota, a autora sinaliza a atualidade do projeto, como parte do projeto de disputa do capital, camuflado de uma certa neutralidade, e que precisa ser enfrentado pela classe trabalhadora.

Já no artigo Encarceramento das mulheres: trabalho, violência e abandono, Yara Elizabeth Alves e Fernando Selmar Rocha Fidalgo analisam as relações sociais de exploração, tanto econômica como de opressão sexual, a que estão submetidas as mulheres encarceradas em unidades prisionais. Por meio de análise documental, observação e entrevistas semiestruturadas com 14 mulheres em privação de liberdade na Região Metropolitana de Belo Horizonte, os autores evidenciam a violência contínua e crescente contra as mulheres, afirmando que capitalismo e patriarcado combinam entre si e se reforçam mutuamente. Os dados apresentados demonstram que as mulheres em cumprimento de pena são, não por mera coincidência, em sua maioria, jovens, negras e com baixo nível de escolaridade, respondendo majoritariamente por um tipo de crime, tráfico ilícito de drogas, cujo envolvimento está relacionado a diferentes fatores e, em especial, à situação de vulnerabilidade em que reproduzem sua existência.

Finalizando a seção, no artigo de Fábio Mansano de Mello e Ana Elizabeth Santos Alves, intitulado História e Memória do Ensino Superior: caminhos de uma investigação, os autores esmiúçam o método do materialismo histórico-dialético, e como fonte documental de pesquisa, indicam duas revistas (Revista Educação e Sociedade; Revista Estudos), trazendo aportes sobre história e memória da educação superior na contemporaneidade (1995-2010). Analisam os contextos em que a educação superior está imersa e o processo de disputa entre dois projetos de ensino superior no Brasil.

Na seção Teses e Dissertações apresentamos os resumos expandidos de duas teses de doutorado defendidas no Programa de Pós-Graduação em Educação 
da Universidade Federal Fluminense, ambas orientadas pela Profa. Dra. Maria Ciavatta, e que merecem leitura atenta e cuidadosa.

A primeira delas, de Renata Reis, intitula-se A "Grande Família" do Instituto Oswaldo Cruz: a contribuição dos trabalhadores auxiliares dos cientistas no início do século $X X$. Sustentada em pesquisa documental de grande envergadura, levantada no Departamento de Arquivo e Documentação da Casa de Oswaldo Cruz/Fiocruz, que conta com mais de 100 fundos e coleções, incluindo fotografias também utilizadas como fonte de pesquisa, a tese se propõe responder quem eram os trabalhadores subalternos da instituição, como se deram as relações destes com os cientistas, qual a sua contribuição para o desenvolvimento da ciência e da saúde pública no Brasil. Suas análises apontam, ao final, para a confirmação da contribuição fundamental do trabalho dos auxiliares para o desenvolvimento da ciência e da saúde pública brasileira. Também indicam que a divisão de classe presente nas relações de trabalho do Instituto Oswaldo Cruz, reproduziu uma divisão social do trabalho que limitou o reconhecimento do trabalho e dos conhecimentos adquiridos pelos auxiliares de laboratório. Ao mesmo tempo, a autora sinaliza que "agindo como sujeitos de suas próprias histórias", estes trabalhadores "buscaram nas brechas da instituição e na construção de relações de reciprocidade entre si, trabalhar e viver suas vidas, ora se submetendo e ora subvertendo o curso da história".

Quanto à tese de Rosângela Aquino da Rosa, intitulada A cultura material da educação profissional, a memória e a história de sua transformação - o acervo de fotografia da Rede Federal de Educação Profissional e Tecnológica (1909-1985), é resultado de uma longa e profícua relação da autora com o acervo de memória institucional do Campus Rio de Janeiro do Instituto Federal de Educação, Ciência e Tecnologia do Rio de Janeiro (IFRJ). Na pesquisa em tela, a autora parte do pressuposto de que imagens fotográficas "são documentos que informam sobre a cultura, o movimento da história, dos sujeitos sociais e da educação vivida". Defendendo a análise das mesmas "em um movimento de intertextualidade", afirma que as fotografias possibilitam a recuperação da historicidade da Educação Profissional. Com base no referencial marxista, Rosa destaca a fotografia "como fonte histórica, como mediação ou processo social complexo subjacente à sua representação" e defende a importância da sua produção social para a compreensão do significado da cultura material presente nas escolas. 
Na seção Memória e Documentos da TN 35 trazemos dois ricos materiais. $\mathrm{O}$ primeiro, refere-se à entrevista do historiador brasileiro José Luiz del Roio, nascido em São Paulo, à "Revista Memória", do Departamento Patrimônio Histórico da ELETROPAULO, publicada em setembro de 1992. Apresentada de forma breve e contundente pela Prof ${ }^{a}$ Dra. Elina Pessanha, coordenadora do Arquivo de Memória Operária do Rio de Janeiro (AMORJ/UFRJ), a entrevista traz um relato emocionante e comprometido de Del Roio sobre sua atuação para a recuperação, organização e divulgação de inúmeros documentos reunidos ao longo de um extenso período histórico por lideranças operárias brasileiras, a maioria delas ligadas ao PCB (Roberto Morena e Astrojildo Pereira em destaque), num momento político grave, que foi a ditadura civil-militar instituída a partir de 1964 no Brasil. Como afirma Pessanha, com sua atuação "del Roio deu uma contribuição inestimável à história de nossa classe trabalhadora e de suas iniciativas de organização e resistência desde o início do século XX". E a Trabalho Necessário tem um imenso prazer em contribuir para que esta memória permaneça viva.

O segundo documento é o memorial de Ana Lúcia Espíndola (In memorian) Breves cartas a uma jovem professora, alguns poemas e outros relatos, apresentado por Léa de Lourdes Calvão da Silva. Em seu memorial, como parte da seleção para professora titular da Universidade Federal do Mato do Grosso do Sul (UFMS), é ressaltada a história/trajetória de uma trabalhadora da educação que se utiliza da ciência com rigor e da arte (a linguagem da poesia) como propulsora dos processos formativos de si e dos outros, demonstrando os diferentes momentos, experiências e espaços educativos da formação humana e um fazer-pensar compartilhado. Em seu memorial é evidenciado o papel indispensável que cumpre o conhecimento elaborado nos espaços públicos de formação, mas, acima de tudo, a responsabilidade do trabalho do educador.

Desejamos uma excelente leitura da TN 35! Entendendo ser a história, a história do processo real de produção da existência humana, também desejamos dias melhores para a história das relações trabalho-educação. Em 2020, e sempre! 